\title{
Arraigo y desarraigo en los inmigrantes colombianos en Santiago de Chile. Incorporación social y transnacionalismo en el contexto de la globalización ${ }^{1}$
}

Nicolás Gissi BARbieri Universidad de Chile. Departamento de Antropología

\section{Introducción}

En la región latinoamericana, Colombia es hoy el país con la mayor emigración y Chile se ha constituido hace cuatro años como uno de los principales lugares de destino de los migrantes Sur-Sur. Históricamente, los Estados de acogida de población colombiana han sido Estados Unidos, España, Venezuela y Ecuador. La primera oleada fue entre 1965 y 1975, la segunda se desarrolló a mediados de la década de los ochenta y la tercera a fines de los años noventa. En esta última década del siglo XX se constató un incremento considerable en los flujos migratorios colombianos debido tanto a factores externos (la crisis económica internacional y el cambio de la legislación migratoria en los países receptores) como internos: el auge del conflicto armado entre guerrilleros, militares y paramilitares, en el contexto de la expansión

$1 \quad$ El presente manuscrito es un producto del proyecto Fondecyt $\mathrm{N}^{\circ} 11130287$. 
del tráfico de drogas y las dificultades económicas especialmente entre 1988 y 1999. Sabemos que los factores externos e internos se encuentran articulados, y tienen como trasfondo los procesos globalizadores de las últimas cuatro décadas, en particular la reforma estructural neoliberal. Estos han aumentado las asimetrías entre los países y las desigualdades al interior de cada sociedad, desembocando en el caso colombiano en importantes retos económicos y políticos debido al colapso en los precios internacionales del café, la principal fuente de recursos del país durante gran parte del siglo XX, así como a la crisis petrolera de principios del siglo XXI, forzando a muchas personas a abandonar su país de origen (Delgado, 2014; OIM, 2012; Cárdenas y Mejía, 2006), habiendo hoy un total de 4’700.000 colombianos residiendo en el exterior (OIM, 2012).

Este contexto mundial y nacional ha generado diversos impulsos para emigrar de Colombia: la búsqueda de nuevas oportunidades laborales y mayores ingresos económicos, la inseguridad social (por recibir amenazas o haber sido víctima de violencia), la salida de familiares y amigos, el mayor desarrollo de otros países, iniciar estudios de posgrado en el extranjero, considerando en todos los casos si las políticas migratorias en otros países son más bien estrictas o permisivas. Estos distintos motivos se suelen sintetizar en razones económicas o políticas; sin embargo, dado que las condiciones políticas y económicas son interdependientes, encontramos un continuum entre lo forzado y lo voluntario de la emigración, por lo que distinguiremos aquí sólo entre "refugiados" y “migrantes". Esto es, entre quienes han escapado de la violencia y amenazas, y quienes enfatizan la búsqueda de mejores oportunidades laborales. Sea cual sea el "gatillante" de la emigración, se han creado poco a poco "cadenas" y "redes" sociales transnacionales a partir de sus regiones de origen.

Estos flujos migratorios se han reorientado durante la última década, incrementándose hacia Chile, Italia, Alemania y México (Mejía, 2012), pasando los colombianos a ser el tercer colectivo de inmigrantes más importante en la sociedad chilena actual. Solamente peruanos (117.925) y argentinos (53.192) los superan en número, siendo ambas naciones fronterizas con Chile. En el caso colombiano, 48.894 personas se contabilizaron en 2013, estableciéndose mayormente en 
la Región Metropolitana (29.822, representando el 66 \%), Región de Antofagasta (4.712, el 10 \%) y Región de Valparaíso (3.476, el 7 \%), de acuerdo a los datos de la encuesta Casen (2013). Se ha constatado así que estamos frente a una movilidad regional, Sur-Sur, que, tal como en las comunidades haitiana y dominicana, aumenta año a año. Hoy son casi 600.000 los inmigrantes en Chile (Subsecretaría de Servicios Sociales 2014), procediendo el 68 \% de países sudamericanos (Cano, Soffia y Martínez, 2009; Stefoni, 2011).

Teniendo presentes estas nuevas realidades sociales en Colombia y Chile, el problema que planteamos en estas páginas se cuestiona: ¿Estamos ante a un mecanismo de redes débiles y de desarraigo, frente a una dinámica de fuertes redes transnacionales y de arraigo en Santiago o ante la constitución de nuevas redes (chilenas) tendientes a la asimilación? Siendo el objetivo de este capítulo conocer las principales características de la incorporación o exclusión (económicas, socioculturales y políticas) de los colombianos residentes en la capital chilena, y cómo el accionar del colectivo inmigrante está generando situaciones de arraigo o desarraigo, de enraizamiento o de permanencia del proyecto migratorio.

\section{Marco referencial: incorporación social, transnacionalismo y arraigo}

Toda migración implica un proyecto, individual y familiar, un plan del sujeto que se desplaza atravesando las fronteras de su país natal. Sueños y objetivos se enfrentarán durante el proceso migratorio a realidades personales y sociales que devendrán en facilitadores o barreras para el cumplimiento de sus expectativas. Para ello hay que considerar las condiciones y las limitantes objetivas que influyen en el logro o no de las aspiraciones. El proyecto constituye la expresión más completa del proceso migratorio: vincula origen, trayecto y destino. Es una transición tensa, pues los individuos se ponen en marcha, pero las decisiones surgen en un contexto más amplio. Hay distintos actores: los que 
se mueven y los que se quedan, los que median y los que encarnan. También intermediarios y receptores directos (familiares o empleadores), así como disímiles instituciones y organizaciones (Izquierdo, 2000).

El migrante se enfrentará, al llegar al lugar de destino, al desafío de la integración en la nueva sociedad en la que ha entrado. La participación en círculos sociales y en unas u otras formas económicas, políticas y socioculturales, dependerá en parte importante de si el individuo se orienta más hacia su sociedad de origen, hacia la nación de acogida (aunque lo sea temporalmente), hacia ambas o si queda marginado en los dos colectivos de referencia. En estas acciones del sujeto habrá un énfasis en el entendimiento o bien en el sentimiento. Esto es, en el estilo de vida urbano, marcado por la economía monetaria y las decisiones racionales, o en la fuerza de las costumbres de su etnicidad (Wirth 1968; Barth 1976; Gellner 1987; Maffesoli 1990). Surgen entonces las preguntas por la vida cotidiana y las elecciones de los inmigrantes, ¿buscarán la dispersión en la gran ciudad, la asimilación y el cálculo utilitarista o bien la concentración barrial, la reproducción cultural y la seguridad que otorgan los comportamientos tradicionales? ¿Cuál es el mejor camino hacia una buena incorporación? ¿Cómo evitar quedar excluido y aislado? ¿Cómo superar la vulnerabilidad de los primeros días en la sociedad de acogida? (Castel 2010; Bauman 2003; Habermas 1999).

Siguiendo a Portes (2012) e Izquierdo (2000), podemos sostener que hay tres actores fundamentales para pensar las posibilidades de arraigo en el contexto de recepción:

1. La población de destino, sus imaginarios y acciones: El ambiente en la sociedad de acogida es más o menos receptivo, dependiendo de la mentalidad del lugar. Esto incluye los medios de opinión pública, diarios y canales de televisión, la existencia de asociaciones de apoyo o de grupos de rechazo, así como el tipo de empresariado, su nivel de compromiso con el desarrollo social y la multiculturalidad. La cultura del trabajo de los empleadores y respeto de derechos.

2. La política migratoria del Estado receptor: La legislación y programas sociales generados desde el Gobierno nacional y local. 
Sus declaraciones y actos. El trato de los funcionarios públicos y los recursos entregados para una buena convivencia en la diversidad. El tipo de visas a que se puede acceder y la demora en la gestión de éstas es un punto crítico.

3. La comunidad de inmigrantes: su solidez y organización social. La extensión y cohesión de la red connacional de apoyo. En esto será clave la época en la que llega cada migrante así como la edad de cada uno. El porcentaje sobre la población nativa y la renta por persona también serán factores que harán más fuerte o más débil al colectivo inmigrante.

La combinación de estos tres elementos genera distintos contextos de integración, que facilitan o dificultan el establecimiento. De ello depende la discriminación o inclusión. La estructura social que espera al recién llegado orientará su camino en una u otra dirección, modificando o reforzando el proyecto migratorio: se asienta o re-emigra, se mezcla o margina, se arraiga o permanece des-arraigado. El proyecto migratorio, sostiene Izquierdo (2000), se agota cuando el migrante mentalmente deja de serlo. La persona puede llevar décadas instalado en otro país, pero mientras permanezca el proyecto sigue siendo un migrante. Puede que haya un último movimiento (¿retorno?) aún por venir. Si ha decidido quedarse "para siempre”, es que ya no tiene proyecto migratorio. Ahora es sedentario, está arraigado. Con el proyecto activo hay convivencia, inserción laboral, aprendizaje, pero no se alcanzará el sentimiento de pertenecer al nuevo lugar. Ahora bien, las actitudes de la sociedad de destino y la política (y ley) migratoria de su Estado, pueden ser similares para dos o más comunidades inmigrantes, siendo preponderante la capacidad de acción y reacción del colectivo que se encuentra desplazando.

Se suele concebir al migrante como un individuo que decide, por una variedad de razones, dejar su hogar para emprender una nueva vida en un país distinto al propio con el anhelo de que en él encontrará aquello de lo que carece en su lugar de origen. Pareciera implicarse que la empresa migratoria conlleva un desarraigo: el abandonar una nación en pos de otra, incluso en aquellos casos donde el migrar es pensado en términos temporales. Tiende a pensarse que la nación 
es el principal objeto de estudio, ya que es a través del cruce de sus fronteras cuando un sujeto adquiere el doble apelativo de emigrante e inmigrante. No obstante, esta perspectiva desestima los fuertes lazos que muchos migrantes mantienen con sus comunidades de origen, ya sea afectivas, económicas, socioculturales e incluso el involucramiento en proyectos políticos. Es este fenómeno el que denominamos como transnacionalismo (que implica cierta regularidad, sostenibilidad y simultaneidad), en el cual los individuos pasan a pertenecer a más de una comunidad nacional, desarrollando sus vidas a través de fronteras (González, 2006; Glick Schiller y Fouron, 2001).

En este sentido, los estudios migratorios de las últimas dos décadas han demostrado que más que asimilación o diáspora, lo que tiende a producirse en la "comunidad" migrante es un tipo más o menos denso de redes transnacionales. El transnacionalismo postula la existencia de nuevas esferas sociales transfronterizas, donde es el migrante y sus vínculos quienes generan formas de socialización ya no exclusivas de una nación, sino que sobreponiendo dos o más naciones a través de diversas conexiones. Estas redes y capital social serán primordiales en los deseos y posibilidades de los sujetos de lograr arraigo en el nuevo medio donde se encuentran.

\section{Metodología}

El método de investigación ha estado guiado por la etnografía, cuya modalidad y objetivos buscan comprender la conducta humana desde el propio marco de referencia de quien actúa. Esta perspectiva permite el estudio de las estructuras sociales y de la acción colectiva, aproximándose a la malla de interacciones que tienen lugar en el proceso histórico-espacial de la vida cotidiana. El presente estudio, respecto al cual este capítulo presenta avances de resultados, permite aprehender el modo en el cual los inmigrantes colombianos desarrollan sus propias "definiciones de la situación". Dado el objeto y sujeto de estudio, optamos por la propuesta de Marcus (2001) denominada "etnografía multi-local o multi-situada", la que considera tanto factores 
objetivos como subjetivos y permite examinar el movimiento de los sujetos en sus distintas trayectorias, lugares y actividades, buscando conectar sitios y quehaceres, conociendo y comprendiendo los imaginarios y prácticas de los actores sociales. De este modo, nos ha interesado cómo los sujetos inmigrantes construyen socio-culturalmente los espacios, transformándolos en lugares, con sentido e identidad (Augé 2007 y 2005).

El trabajo de campo se llevó a cabo fundamentalmente en las comunas de Santiago (central), Quilicura (sub-urbana), Recoleta y Providencia (peri-centrales), en la ciudad de Santiago, entre 2014 y 2016. Es de destacar que Quilicura es la comuna de la Región Metropolitana (RM) con mayor porcentaje de población inmigrante $(18.2 \%$ ) y que considerando solo los inmigrantes colombianos, Santiago Centro es la comuna con mayor porcentaje $(59.22 \%)$ de población colombiana en la RM (Casen, 2013).

Las tres técnicas de recolección primaria utilizadas han sido la observación participante, la entrevista en profundidad y la historia de vida. De este modo, hemos aplicado la denominada "triangulación intra-metodológica" (Vasilachis 1992), complementando diversas técnicas para el estudio del mismo fenómeno, asumiendo la complejidad multifactorial de la realidad social, evaluando y mejorando la información obtenida por cada una de éstas. El contenido de las entrevistas en profundidad (50) e historias de vida (cuatro) fueron analizados a través de una malla temática que se construyó a partir de la pauta de entrevista etnográfica. El proceso de codificación se realizó paralelamente al de categorización -incluyendo categorías emergentes-, pues mediante la comparación constante simultáneamente se codifican y analizan datos para desarrollar conceptos, de acuerdo a los planteamientos de la Teoría Fundamentada (Trinidad, Carrero y Soriano 2006). Finalmente, para visualizar recurrencias empíricas se utilizó el software Atlas-ti.

Así mismo, hemos recolectado información a través de fuentes secundarias, revisando las bases de datos de organismos públicos, nacionales e internacionales, como la Organización Internacional para las Migraciones (OIM), la Agencia de la ONU para los Refugiados (ACNUR), la encuesta Casen 2013 del Ministerio de Desarrollo Social 
y el Departamento de Extranjería y Migración (DEM), del Ministerio del Interior de Chile.

\section{Análisis de resultados}

\section{Proyecto migratorio y llegada a Chile}

Respecto a los motivos de su salida de Colombia y llegada a Chile, podemos distinguir entre los migrantes "económicos" o laborales y los migrantes "políticos" o por seguridad personal, esto es, entre quienes decidieron voluntariamente movilizarse para mejorar su situación económica, y quienes se vieron forzados a abandonar su país por encontrarse en una situación de peligro en Colombia, circunstancias que se asocian habitualmente a espacio rurales y que es más señalada por quienes residían en el sur de Colombia, en el valle del Cauca.

En el caso de los "migrantes", son personas que han visto mayores posibilidades de desarrollo profesional en Chile pues sus carreras u oficios estarían "estancado" en Colombia, siendo particularmente relevante el caso de la temprana llegada de los odontólogos y otras profesiones médicas (enfermeras, kinesiólogos, médicos, como también químicos farmacéuticos). Algunos (pero en menor medida) se encuentran haciendo estudios de posgrado en Chile con expectativas de mejorar su estatus laboral y quienes han decidido desplazarse para no separarse de su pareja (colombiana o chilena). Todos celebran la gran cantidad de ofertas laborales que habría en Santiago. Destacan los profesionales (ingenieros de sistemas e industriales) que han sido enviados por la empresa transnacional en la que trabajaban en Colombia a una sucursal abierta en Chile, identificándose con el estrato socioeconómico 5, el segundo más alto, de acuerdo a las categorías usadas en Colombia ${ }^{2}$.

2 En Colombia se reconocen seis estratos socio-económicos, siendo seis el más alto y uno el más bajo, según los barrios y casas donde residan. Estas identificaciones de clase o estrato se tienden a reproducir en Chile, aunque no son 
En el caso de los "refugiados", se trata de personas que han recibido amenazas en el contexto del conflicto armado en Colombia. Esta situación ha afectado tanto a individuos de clase alta como baja. Quienes se caracterizaban por una buena situación económica temían ser asaltados o secuestrados y quienes tenían poco dinero (campesinos y obreros) señalan haber recibido amenazas por no pago de deudas a personas o instituciones comerciales.

En ambos casos, el factor macroeconómico (aunque poco se menciona por los entrevistados) actúa como trasfondo de estas migraciones, pues aumentó la cesantía y sub-empleo tanto de productores y empleados públicos como en las empresas. España, Estados Unidos, Venezuela y Ecuador, son los países que suelen nombrar los entrevistados pues en ellos tienen parientes, en cambio se mencionan como países a los cuales podrían migrar más adelante Australia y Canadá. Respecto a los motivos para elegir Chile, se suele destacar la positiva imagen del país tanto en términos económicos (crecimiento y estabilidad) como políticos (seguridad, tranquilidad). Este positivo clima nacional generaría que en algunas áreas laborales haya mayor disponibilidad de puestos de trabajo o serían mejor remunerados, así como la existencia de algunos posgrados (como en ciencias sociales y economía) con un alto prestigio. Sin embargo, en no pocas ocasiones sólo se señala como razón para venir a Chile la referencia de algún compatriota que vivía en Chile, amigos o compañeros de universidad o trabajo: "Porque había un amigo acá, un conocido que dijo que estaba bueno, que se pagaba bien, que se podía ganar buena plata, así que vinimos a probar suerte”, como dijo Alex (34 años, afrocolombiano). Otra razón que señalan los entrevistados son las facilidades de ingreso, pudiéndose permanecer legalmente en condición de turista durante tres meses. En el caso de los refugiados, se releva también el reconocimiento de Chile como país de acogida para solicitantes de asilo, pues Chile es uno de los siete países latinoamericanos que forman parte del Comité Ejecutivo de ACNUR. 
Destaca entre la población afro-colombiana su proveniencia desde Cali, el puerto de Buenaventura y sus alrededores en el Valle del Cauca, donde viven los "vallunos", en el sur de Colombia, colindando con el océano Pacífico. Esta población suele ser asociada a los estratos más bajos debido a su menor cantidad de años de estudio, opuestamente a quienes provienen desde el océano Atlántico, los “costeños”, quienes se destacan por tener una mayor cantidad de años de escolaridad. Tanto la inseguridad debido al conflicto armado como las experiencias laborales de inestabilidad y bajos ingresos, son motivos indicados para emigrar de su región y país de nacimiento. Al respecto afirmó Jonathan (31 años, mestizo): "En Cali y Buenaventura hay mucha violencia, o sea la guerrilla y las Farc, todo, se han tomado parte de Buenaventura, más que todo Buenaventura, están matando mucha gente y aparte que así el trabajo también disminuye, no hay inversión, entonces el problema que hay en Buenaventura es muy grande... no ha terminado eso y yo creo que no va a terminar, eso pareciera que fuera algo que va a tener siempre Colombia, yo no le veo salida... yo creo que siempre van a pelear, porque igual el Gobierno apoya a esos, esos grupos entonces no... para mí son lo mismo, Gobierno y Farc, la misma corrupción”.

\section{Localidades de origen en Colombia}

Los migrantes señalan que provienen directamente de los grandes centros urbanos, Bogotá, Medellín, Cartagena de Indias y Barranquilla, o que tienen un origen en un pueblo pero que su primer trabajo (y residencia) fue en alguna de estas ciudades, en el centro o norte de Colombia. Ellos, en su mayoría de "raza" blanca, han llegado en avión a Santiago. Al tener una profesión, suelen tener oportunidades de desarrollo laboral e incluso algunos acceden a trabajos con contratos y altas remuneraciones, como los consultores SAP, una de las empresas de software más importantes del mundo, especializada en el desarrollo de programas para la gestión de empresas.

En el caso de los refugiados, en cambio, suelen ser originarios de zonas rurales, donde también vivían antes de su forzado desplazamiento. Destaca la procedencia desde Cali y Buenaventura, en la zona suroeste de Colombia. En sus relatos, manifiestan haber viajado en bus primero a la 
capital y desde Bogotá a Arica, en la frontera norte de Chile, donde suelen haber vivido experiencias de mal trato, frustrándose el denominado "sueño chileno". Son en su mayoría de "raza" negra, afrocolombianos. Una vez que han podido, se han trasladado a Santiago. Sus itinerarios de desplazamiento son tendencialmente mayores, siendo no menor los casos en que estuvieron un tiempo viviendo en Ecuador antes de tener que salir de ese país y viajar a Chile. Otros llegan a Tacna, en el sur de Perú, cruzan ilegalmente por Bolivia, llegando a Iquique, guiados por "jaladores" peruanos. Llegan al "rebusque" de trabajos para poder sobrevivir. Entre los inmigrantes colombianos hay una evidente diferencia socioeconómica, destacando entre todos una alta conciencia de clase o de estrato. Al respecto, los migrantes de clase alta señalan que "hay colombianos de otro tipo" que generan una imagen negativa del país, por lo que las políticas migratorias chilenas debieran endurecerse. También los migrantes que han logrado un ascenso socioeconómico en Chile concuerdan en que es muy flexible la ley, debiendo diferenciarse según los distintos tipos de sujetos: "No me junto con esa clase de personas, los que 'se mueven'”, dice Alex, refiriéndose a quienes se dedican a actividades ilegales.

\section{Aspectos económicos}

El envío de remesas representa la principal vinculación de tipo económico entre los inmigrantes colombianos y sus familias. De los 50 entrevistados, 24 declaran enviar o haber enviado dinero a sus familiares, y resulta interesante mencionar que no pareciera existir un sesgo por sexo, ya que estos se dividen exactamente a la mitad. Tampoco pareciera que el nivel educacional afecta necesariamente si se envía o no dinero. La principal razón esgrimida para enviar remesas es la necesidad de apoyar a familiares cercanos que permanecen en Colombia, padres y hermanos pequeños. Nueve de los entrevistados aseguran enviar dinero periódicamente para estos fines, incluyendo el apoyo a padres enfermos. Tres entrevistados declaran enviar remesas pero de forma esporádica o para cubrir contingencias de la familia. En dos casos el envío de dinero a Colombia ha sido con fines personales, como el caso de Lorena quien mantiene un perro allá que es cuidado por su hermana, y de Diego quien realiza giros a una cuenta que mantiene en 
Colombia para "su sustento", aunque menciona que "dado el caso de que se requiera, ellos ya tienen acceso a mi cuenta". Por último, cinco entrevistados mencionan que enviaban remesas pero ya no lo hacen, ya sea "porque lo hice toda la vida y pensé que es el momento en que yo me libere de ese yugo" o simplemente porque "antes éramos como más constantes. Pero ahora no, nos hemos dejado”.

La circulación de alimentos es otra categoría importante, ya que hace referencia a añorar una cotidianidad perdida, pues "las prácticas alimentarias representan una manera de acercamiento a la experiencia del destierro en relación con la identidad" (Gómez, 2014, 39). No resulta por lo tanto extraño que más de dos tercios de los entrevistados destaquen el envío de alimentos desde Colombia como uno de los principales vínculos, llegando incluso a comentar el carácter "sagrado" del café traído desde su país de origen o al preguntarle a otra entrevistada qué pide a sus familiares, obtener la respuesta de "pura alimentación no más". Muchos entrevistados piden a sus familias que les envíen (o traen a Chile cuando realizan visitas) alimentos que no encuentran fácilmente en el país (a pesar de que muchos mencionan que cada vez hay mayor disponibilidad a nivel local) como "bocadillos", "areparina" para hacer arepas y "panela". Nuevamente no pareciera haber un sesgo por sexo o por nivel educacional.

El envío de regalos desde y hacia Colombia también constituye un vínculo importante y como los anteriores, principalmente se reduce al ámbito familiar y de amistades cercanas. De Chile llevan vino, pisco y derivados de éste, junto a artesanías típicas y lapislázuli, destacando algunos entrevistados que no encuentran objetos o artesanías representativas del país, como por ejemplo Diego, quien explica que ha "tenido problemas con eso porque lo único que encuentro para llevar es vino, así como representativo es como llegar con vino". Resulta interesante que algunos entrevistados mencionan enviar o recibir bienes debido a que resultan más económicos que en el país de origen. Diana, por ejemplo, señala que su madre le envía las pastillas anticonceptivas desde Colombia debido a que considera que su valor es muy elevado acá. Desde Chile, en cambio se envía (o la familia y amigos llevan cuando visitan) especialmente objetos tecnológicos. Cabe destacar además la mención que realiza Eduardo sobre la formación de una cámara de 
comercio "colombo-chilena" cuyo objetivo es fortalecer las relaciones económicas entre los países a través del involucramiento de distintas empresas para facilitar negocios.

Los vínculos económicos arriba descritos pueden ser considerados de carácter transnacional debido a que tienden a ser regulares (lo que es más apreciable en el caso de quienes envían remesas periódicamente) y sostenibles, ya que como puede ser apreciado en el caso de la circulación de alimentos, suele perdurar a pesar del paso de largos periodos de tiempo. Sin embargo, estos lazos transnacionales están limitados exclusivamente al círculo cercano del migrante, generalmente compuesto por el núcleo familiar y cuatro o cinco amigos.

\section{Dimensión sociocultural}

La dimensión sociocultural abarca una enorme variedad de vínculos y contactos entre el migrante y Colombia, como visitas desde y hacia este país y la comunicación regular a través de distintos medios. Fundamentalmente debe comprenderse este ámbito como aquel donde priman aquellas vinculaciones de tipo afectivo, y aquellas que permiten cierta continuidad entre el hogar y sociedad que se deja atrás, y el nuevo entorno, incluyendo una gran variedad de expresiones desde religiosas hasta deportivas. Es quizás en esta dimensión donde es más visible el transnacionalismo desde la perspectiva de que el migrante es capaz de mantener una relación continua entre dos lugares, generando uno nuevo: la esfera social transnacional.

Las visitas realizadas por el inmigrante colombiano hacia su país, y las visitas realizadas por sus familiares y amigos colombianos a Chile constituyen un importante nexo, ya que significan un contacto directo que permite mantener y revitalizar relaciones sociales involucrando todos los sentidos. De los 50 entrevistados, 29 declaran haber visitado o recibido visitas desde Colombia, y de estos 25 comentan haber visitado Colombia al menos una vez desde el viaje inicial a Chile. Destaca que 15 de los entrevistados visitan Colombia con regularidad, incluyendo algunos que intentan viajar todos los años. Sin embargo pareciera existir una fuerte limitación económica que define quiénes pueden o no viajar. Sólo cuatro de los entrevistados que participan en este tipo de vínculos no tienen algún tipo de estudios superiores, y 
de estos cuatro ninguno viaja regularmente, aunque un entrevistado -Jaime- declara que aunque él no ha viajado, sí lo han hecho sus hijas y señora con cierta regularidad. Las principales razones esgrimidas para viajar a Colombia tienen relación con la añoranza de la familia y costumbres como comenta Eduardo: “mira yo también me siento privilegiado en ese sentido (viajar a Colombia), porque cuando uno es un inmigrante en un país, uno añora su país y viajar e ir a ver la familia y a los amigos y comer la comida de uno y volver a escuchar su música”. La mayoría de estos 29 entrevistados dicen ser visitados ya sea por parientes o amigos, lo que genera cierta circularidad cultural que se ve expresada en la adquisición de nuevos elementos culturales como el gusto por el vino chileno de algunos colombianos, el incremento de la disponibilidad de alimentos colombianos en Santiago e incluso la apropiación de modismos chilenos, como comenta Tatiana: "Ya cuando uno empieza a hacer su vida solo empiezas a adaptar, y a viajar tanto, empiezas a adaptar culturas de diferentes lados”.

Resulta interesante analizar las respuestas que los entrevistados entregan a la pregunta "Cuando tiene algún problema, ¿a quién le pide ayuda (parientes, amigos, organismos públicos, empresarios)?” Ya que es frente a la adversidad cuando es más fácil vislumbrar la existencia de redes comunitarias. En el caso de los colombianos en Santiago, las respuestas indican una fuerte desconfianza hacia todo lo que no sea el círculo cercano del migrante, específicamente el núcleo familiar que se encuentra en Chile o los amigos próximos -muchas veces amistades traídas desde Colombia- en caso de carecer de familia en el país. Se verifica así cierto individualismo colombiano, ya advertido por autores como Puyana (2005) y Yunis (2004). De las 22 respuestas a esta pregunta, 14 dicen que recurrirían a amigos que en la práctica funcionan como una familia, como plantea Édgar: "Mis amigos que son como mi familia acá" o Tatiana: "Yo ya como que creé lazos más familiares, vínculos más familiares con gente de acá, con amigos de acá que con mi propia familia". Tan sólo dos respuestas hacen referencia a solidaridad institucional, puntualmente a una asociación de apoyo a refugiados donde ayudan a conseguir trabajo y dar protección (Vanessa) y a "un núcleo familiar que le dicen acción social. 
La acción social que es la que ayuda a la gente...como a las personas que han sido desplazadas de sus lugares por la violencia" (Leonardo).

Esta aparente falta de vida comunitaria se aprecia fuertemente en la poca participación y falta de interés que los entrevistados declaran tener sobre cualquier tipo de asociación que involucre a los colombianos en Santiago. Aunque se señala que "hay muchos colombianos que participan (en las iglesias)", ninguno de los entrevistados sostiene participar activamente en alguna institución de este tipo. De modo semejante, no pareciera existir gran interés por participar en asociaciones deportivas que reúnan a miembros de la comunidad colombiana, sólo hay una mención a un campeonato de fútbol conformado por equipos de distintas nacionalidades con el objetivo de promover la integración. Respecto a las instituciones de migrantes, tan sólo seis de los 50 entrevistados dice participar o haber participado en alguna institución de este tipo y sólo una dice haber asistido con cierta regularidad por algo más de un año al centro PRISMA de la Universidad Alberto Hurtado donde recibía atención psicológica. Es de destacar que en este caso, la entrevistada comenta que en el centro quienes prestaban la atención eran chilenos. Aunque no es concluyente debido al bajo número que dice haber participado en este tipo de instituciones, cinco respuestas pertenecen a mujeres por lo que sería interesante profundizar en investigaciones futuras sobre si existe algún sesgo por sexo.

Esta falta de participación en organizaciones que reúnan a colombianos es explicada por los entrevistados principalmente por tres razones: la falta de interés, la falta de necesidad o el desconocimiento. De los 26 entrevistados que mencionan explícitamente no participar en ningún tipo de organización, 10 dicen que la principal razón por la que no participan es que carecen de información. Este desconocimiento pareciera derivar más que nada de una falta de interés o necesidad, ya que quienes dicen no tener información expresan frases como "la información hay que buscarla, no es que lleguen a uno y le digan, hay que buscarla. O sea yo necesito algo y voy y pregunto". Además, muchos comentan que las únicas instituciones que conocen y utilizan para temas migratorios son el Consulado y Extranjería, y que incluso, a pesar de que el Consulado realiza ac- 
tividades, no asisten ya que prefieren sociabilizar con el grupo de amigos, o simplemente no les interesa. De quienes declaran no participar por falta de interés o necesidad, nuevamente surge el tema de la autosuficiencia y la búsqueda de apoyo en el seno de la familia y los amigos cercanos. Varios comentan que no recurrirían o recurrieron porque al llegar a Chile simplemente se "valieron por sus propios medios" para buscar trabajo y adaptarse al nuevo entorno. En cuanto a la existencia de diferencias por sexo o nivel educacional, pareciera no influir y ser más bien una postura transversal.

Un último -y probablemente más importante vínculo- son los contactos entre familiares y amigos en Santiago y Colombia realizados a través del teléfono o nuevas tecnologías como Skype, Facebook o WhatsApp. Por otra parte, 26 de los/entrevistados dicen tener contacto regular con Colombia, de los cuales 18 estiman que esta frecuencia es diaria. Los avances en las tecnologías han permitido una fuerte disminución en el costo de las comunicaciones, pues el acceso a cualquier "teléfono inteligente" permite interactuar en una gran variedad de redes sociales y aplicaciones para comunicarse a muy bajo, o a ningún costo, que han posibilitado un grado de conexión permanente, revolucionando la concepción de distancia, como comenta Alejandro: “con esto de la tecnología...sigo sin querer ahí cerca”. La comunicación que permiten aplicaciones como WhatsApp y Facebook ha generado una "ventana" hacia la cotidianidad del que está lejos, permitiendo el conocimiento de aquellos detalles que generan la sensación de que la distancia pareciera no existir. Así, las nuevas tecnologías permiten mantener y recrear redes sociales transnacionales a través de los intercambios espontáneos y en tiempo real de información selectiva y relevante.

Los aportes realizados por esta revolución en las tecnologías son destacados y reconocidos por la gran mayoría de quienes dicen mantener una comunicación frecuente con amigos y familiares en Colombia. Por ejemplo, Lina comenta que "antes era más difícil poder comunicarse con la familia estando fuera del país o incluso estando fuera de la ciudad, ya no lo es tanto, la tecnología ha avanzado mucho". Liliana resume este planteamiento al asegurar que "como que no me desligo del todo de Colombia, entonces en el día a día sigo viviendo con ellos”. 
Puntualmente, de estas nuevas tecnologías, las más mencionadas son, por un lado, WhatsApp, ya que permite el envío de pequeños mensajes que no necesariamente deben ser respondidos al momento, por lo que puede ser integrada en el día a día y es compatible con las labores cotidianas sin necesariamente interrumpir el trabajo, como lo hace Leonardo: "el WhatsApp, estoy trabajando y hablando con un tío, hablando con un primo, hablando con un amigo". Además WhatsApp tiene la particular característica de crear grupos donde pueden participar simultáneamente varios individuos simulando las características de una conversación cara a cara entre amigos o familiares como comenta Anita, quien mantiene un chat familiar en el que participa a diario y a través del cual envía y recibe fotografías que le permiten seguir los cambios que vive su familia sin importar la distancia. Otro ejemplo es el de Tatiana quien también utiliza WhatsApp a diario y envía y recibe fotografías: "Ahora de hecho trato de mostrarles un poco mi nueva cultura y ellos también como de amarrarme quizás al recuerdo, de no sé, me mandan fotos”. En este caso, además de permitir la continuidad de las relaciones familiares, se menciona cómo se introducen nuevos elementos culturales ya que la entrevistada menciona que busca mostrarle a su familia su nueva cultura, “mostrándoles pa' que abran un poco la cabeza”. Varios mencionan que utilizan Facebook y Facebook Messenger, que viene a cumplir una función semejante.

Skype y otras aplicaciones usadas para realizar videollamadas también fueron mencionadas por muchos entrevistados ya que, a pesar de que requieren más tiempo para utilizarse y es más complicado introducirlas en las labores diarias, permiten un nivel de intimidad mayor al poder ver y hablar simultáneamente con el ser querido. Surelis, por ejemplo, recarga mensualmente dinero en Skype para comunicarse con su esposo; o Eduardo, quien destaca los positivos cambios que ha generado esta plataforma: "no solo hablamos sino que nos vemos, así que, con la familia permanentemente; es decir, no se puede perder esa, hay una necesidad vital de seguir hablando con la gente y sobre todo ahora que la tecnología te facilita tanto esa cosa, antes se gastaba mucha plata en la larga distancia internacional, ahora ya no, eso se acabó". Estas aplicaciones permiten incluso un uso creativo como 
lo hace Anita: "todos los viernes tenemos una cita con ellos, todos los viernes carreteamos con ellos, ellos se conectan con sus cositas pa' picar y nosotros también acá". Cabe destacar que, aunque estas nuevas tecnologías han revolucionado las comunicaciones, varios comentan que aún utilizan las llamadas telefónicas, aunque sea de forma complementaria, ya que en muchos casos se relacionan con algún pariente que no sabe cómo utilizarlas, como Surelis: "mi mamá como no sabe mucho de tecnología entonces me toca llamarle al celular, entonces yo llamo al celular de mi mamá casi todos los días”.

\section{5. Ámbito político}

Respecto a la dimensión política, el Estado colombiano ha destacado por intentar mantener a los ciudadanos que han dejado el país vinculados al quehacer de la política nacional a través de distintas medidas, como permitir el voto a ciudadanos en el extranjero. Sin embargo en el caso de los colombianos en Santiago no pareciera dar grandes resultados, ya que de los 50 entrevistados sólo dos mencionan algún tipo de participación política. Se describe una emergente organización con propósitos de mutua defensa, debido a experiencias de discriminación en los hospitales, en el transporte público, de los hijos en las escuelas, en el momento que se busca arrendar una vivienda, en supermercados, en trabajos de baja calificación, así como en la frontera y en el Consulado. Estos malos tratos de parte de chilenos se habrían agravado desde hace cinco años, cuando aumentó la inmigración colombiana en Chile.

Este ámbito es más nombrado por los refugiados (hay 964 refugiados colombianos en Chile, de acuerdo al DEM, 2014) identificando algunos de los entrevistados a la Asociación de Mujeres Refugiadas Colombianas, a la Organización de Refugiados Colombianos en Chile y a la Asociación de Inmigrantes MIRA Chile, pero sus participaciones se destacan por la poca regularidad. 


\section{Conclusiones}

Los vínculos entre colombianos que poseen cierta regularidad, sostenibilidad y simultaneidad son el envío de remesas, la circulación de bienes y alimentos, las visitas realizadas desde y hacia Colombia, y los contactos a través de distintas tecnologías (WhatsApp, Facebook o Skype), no habiendo un sesgo por sexo o por nivel educacional. Señalan haber viajado más de una vez a su país de origen, en vacaciones, en fiestas religiosas nacionales o por motivos familiares. Sin embargo, esos viajes empezaron a declinar lentamente con el paso de los años residiendo en Chile, en parte importante por el fallecimiento de familiares y amigos o porque ellos también emigraron de sus países. Un segundo argumento sostenido es que muchas veces las realidades familiares que dejaron en sus países ya han cambiado bastante, por lo que se sienten menos necesarios allá. Un tercer punto señalado es que prefieren que sus familiares viajen a Chile para que conozcan dónde están establecidos, especialmente Santiago, ciudad que es muy valorada. Una cuarta razón que se repite es haber optado por gastar sus dineros en mejorar su calidad de vida en Chile y no en nuevos viajes. Una quinta y última explicación es que una vez que a un migrante le ha ido bien con su trabajo o negocio ("meta cumplida"), invita a su familia a que se venga a vivir con él/ella a Santiago ("Yo ya como que creé lazos familiares, vínculos más familiares con gente de acá, con amigos de acá que con mi propia familia”). Ahora bien, si no les ha ido económicamente como esperaban, resurge la emocionalidad por la distancia de la patria de origen, y si a esto se suma haber vivido experiencias de racismo o xenofobia se refuerza la indefinición del proyecto generándose el desarraigo. El racismo es entonces un agravante, más que la principal razón esgrimida para pensar en el retorno.

En la medida que va aumentando el arraigo en Chile, las comunicaciones son cada vez menos cara a cara y más vía medios tecnológicos: "Como que no me desligo del todo de Colombia, entonces en el día a día sigo viviendo con ellos”. Además, año a año se ha ido consolidando la reproducción de prácticas tradicionales en Chile, por lo que sus iniciales nostalgias por tales festividades tienden a perder 
fuerza, pese a que su presencia en éstas es junto a su núcleo social, pues más que una grande y sólida comunidad, el colectivo colombiano se caracteriza por ser un conjunto fragmentado de "comunidades mínimas" o íntimas, dados los mutuos recelos entre quienes no se conocen (o mientras no se conozcan).

La participación en instituciones que reúnan a connacionales es esporádica, existiendo una falta generalizada de interés que merma el surgimiento de una comunidad cohesionada, identificándose una motivación a reunirse en los ámbitos sociocultural y económico pero no en el político, lo que es evidenciado directamente por los propios entrevistados: "igual siento que un poco la mayoría de colombianos que viene acá no se junta mucho entre sí”. La reciprocidad tiende a estar limitada a redes sociales estrechas de amigos y familiares con similares características de clase, localidad de origen y "raza", por lo que pareciera que las causas de tan débil capital social deben ser buscadas en características propias de su historia, marcada por décadas de violencia que han polarizado a la sociedad generando desconfianzas que se reproducen al emigrar. Estas redes transnacionales suelen implicar contactos en Estados Unidos, España, Inglaterra y Francia, así como en Venezuela, Ecuador y Panamá en América Latina, lo que va paulatinamente conformando una identidad cosmopolita, poco a poco pos-nacional.

\section{Bibliografía}

Agencia de la ONU para los Refugiados (ACNUR). www.acnur.org/t3/donde-trabaja/america/chile/ (Recuperado el 02 marzo de 2016).

Anderson, B., (1993). Comunidades imaginadas. Reflexiones sobre el origen y la difusión del nacionalismo. México: FCE.

Augé, M. (2007). Por una antropología de la movilidad. Barcelona: Gedisa.

Augé, M. (2005). Los no lugares. Espacios del anonimato. Una antropología de la sobremodernidad. Barcelona: Gedisa.

Barth, F. (1976). Los grupos étnicos y sus fronteras. México: FCE. 
Bauman, Z. (2003). Comunidad. En busca de seguridad en un mundo hostil. Madrid: Siglo XXI.

Cano, M., Soffia, M. y Martínez, J. (2009). “Conocer para legislar y hacer política: los desafíos de Chile ante un nuevo escenario migratorio”, CEPAL, Población y Desarrollo, Nº8. https://www.academia.edu/3694852/ Cano_M.V._Soffia_M._Mart\%C3\%ADnez_J._2009_Conocer_para_legislar_y_hacer_pol\%C3\%ADtica_los_desaf\%C3\%ADos_de_Chile_ante_ un_nuevo_escenario_migratorio_

Cárdenas, M. y Mejía, C. (2006). “Migraciones Internacionales en Colombia: ¿qué sabemos?”, Working Paper Series - Documentos de Trabajo, № 30. En: http://www.iadb.org/intal/intalcdi/PE/2009/02989.pdf

Casen. (2013). Inmigrantes. Síntesis de resultados. Ministerio de Desarrollo Social, Santiago. www.ministeriodesarrollosocial.gob.cl/btca/txtcompleto/ midesocial/casen2013-inmigrantes.pdf (recuperado el 08 marzo de 2016).

Castel, R. (2010). El ascenso de las incertidumbres. Trabajo, protecciones, estatuto del individuo. Buenos Aires: FCE.

Delgado, R. (2014). “Globalización neoliberal y migración forzada: Una mirada desde el Sur", en Movilidad humana y diversidad social en un contexto de crisis económica internacional, Madrid, Trotta.

Departamento de Extranjería y Migración (DEM), (2014). Anuario Estadístico Nacional, Ministerio del Interior de Chile, Santiago. www.extranjeria.gob.cl/media/2016/02/Anuario-Estad\%C3\% ADstico-NacionalMigraci\%C3\%B3n-en-Chile-2005-2014.pdf (recuperado el 14 marzo de 2016).

Elías, N. y Scotson, J. (2016 [1965]). Establecidos y marginados. Una investigación sociológica sobre problemas comunitarios. México, FCE.

Geertz, C. (2005). La interpretación de las culturas. Barcelona: Gedisa.

Geertz, C. (1996). Los usos de la diversidad. Barcelona: Paidós.

Gellner, E. (1987). Cultura, identidad y política. El nacionalismo y los nuevos cambios sociales. Barcelona: Gedisa.

Glick Schiller, N. y Fouron, G. (2001). Georges Woke Up Laughing: LongDistance Nationalism and the Search for Home. Durham: Duke University Press Books. 
González, M. (2006). “Migración, desarrollo y transnacionalismo. Conceptos básicos”, en Colombia: migración, transnacionalismo y desplazamiento, Gerardo Ardila (ed.), Universidad Nacional de Colombia, Facultad de Ciencias Humanas y Ministerio de Relaciones Exteriores, Bogotá. En: http://www.bdigital.unal.edu.co/785/6/257_-_5_Capi_4.pdf

Guarnizo, L.E. (2008). Londres Latina. La presencia colombiana en la capital británica. México: Universidad de Zacatecas y Porrúa.

Habermas, J. (1999). La inclusión del otro. Estudios de teoría política. Barcelona: Paidós.

Instituto Nacional de Derechos Humanos (INDH). (2015). Informe anual 2015. Situación de los derechos humanos en Chile. Santiago. http:// indh.cl/wp-content/uploads/2015/12/informe-anual/Informe-AnualINDH-2015.pdf (recuperado el 17 marzo de 2016).

Izquierdo, A. (2000). "El proyecto migratorio y la integración de los extranjeros", en Revista Estudios de Juventud N49, INJUVE, Madrid. www. injuve.es/sites/default/files/Revista49-3.pdf (recuperado el 05 marzo de 2016).

Maffesoli, M. (1990). El tiempo de las tribus. Barcelona: Icaria.

Marcus, G. (2001). "Etnografía en/del sistema mundo. El surgimiento de la etnografía multilocal”, Alteridades 11 (22), 111-127. www.unc.edu/ restrepo/trabajo\%20de\%20grado/etnografia \%20multilocal-marcus.pdf (recuperado el 20 marzo de 2016).

Mejía, W. (2012). “Colombia y las migraciones internacionales. Evolución reciente y panorama actual a partir de las cifras”. http://www.scielo.br/ pdf/remhu/v20n39/v20n39a10

(recuperado el 25 marzo de 2016).

OIM, (2012). “Perfil migratorio de Colombia 2012”. Bogotá. file://C:/Users/ Nicol\%C3\%A1s/Downloads/1_Perfil_Migratorio_de_Colombia_2012.pdf

Portes, A. (2012). Sociología económica de las migraciones internacionales. Barcelona: Anthropos.

Puyana, G. (2005). ¿Cómo somos? Los colombianos. Reflexiones sobre nuestra idiosincrasia y cultura. Bogotá: Panamericana.

Stefoni, C. (2011). Perfil migratorio de Chile. OIM, Buenos Aires. En: http:// priem.cl/wp-content/uploads/2015/04/Stefoni_Perfil-Migratorio-de-Chile. pdf 
Subsecretaría de Servicios Sociales, Ministerio de Desarrollo Social, (2014). Providing equal opportunities: What Works in the integration of youth with a migration background?

Taylor, C. (1993). El multiculturalismo y "la política del reconocimiento". México: FCE.

Trinidad, A.; Carrero, V. y Soriano, R. (2006). Teoría Fundamentada. Grounded Theory. La construcción de la teoría a través del análisis interpretacional, Cuadernos Metodológicos 37, Madrid: Centro de Investigaciones Sociológicas.

Vasilachis de Gialdino, I. (1992). Métodos cualitativos 1. Los problemas teórico-epistemológicos, Buenos Aires: Centro editor de América Latina.

Wirth, L. (1968). El urbanismo como modo de vida, Buenos Aires: Nueva Visión.

Yunis, E. (2004). ¿Por qué somos así? ¿Qué pasó en Colombia? Análisis del mestizaje. Bogotá: Temis. 
